\title{
NEUTRON DIFFRACTION MEASUREMENT OF AS-CAST RESIDUAL STRESSES IN AA7050 ROLLING PLATE ING OTS: INFLUENCE OF A WIPER
}

\author{
J.-M. Drezet ${ }^{1}$, P. Celle ${ }^{2}$, O. Ribaud ${ }^{2}$ and Th. Pirling ${ }^{3}$ \\ ${ }^{1}$ LSMX, Ecole Polytechnique Fédérale de Lausanne, \\ Station 12, CH-1015 Lausanne, Switzerland \\ jean-marie.drezet@epfl.ch \\ ${ }^{2}$ Constellium, Centre de Recherches de Voreppe (CRV) \\ 725 rue Aristide Bergès - CS-10027 \\ F-38341 Voreppe Cedex, France \\ ${ }^{3}$ Institut Laue Langevin, ILL-Grenoble \\ F-38042 Grenoble, France
}

Keywords: Aluminum direct chill casting, rolling plate ingots, residual stresses, neutron diffraction, thermomechanical modeling

\begin{abstract}
A bstract
During casting, thermally induced deformations give birth to ingot distortions and residual stresses. For some high strength alloys, ingot cracking can happen during casting per se or during cooling down. Ingot distortions such as rolling face pull-in, but curl and but swell are rather easy to quantify as opposed to internal stresses. As aluminium is rather transparent to neutrons, residual stress measurements using neutron diffraction appeared to be a good way to validate the thermomechanical models aimed at simulating the stress build-up during casting. This technique has been applied to DC cast AA7050 rolling plate ingots with special attention to the stress generation in the transient start-up phase, i.e. in the foot of the ingot. Additional results using the hole drilling method complement the measurements. The measured stress distributions are compared with the results of a numerical model of DC casting for ingots cast with and without a wiper.
\end{abstract}

\section{Introduction}

In the fabrication of aluminum rolling plates, the first step is the semi-continuous casting of a rectangular ingot. The most commonly used process is known as direct chill (DC) casting [1]. This process gives rise to large thermally induced strains that lead to several types of casting defects (distortions, cold cracks, porosity, solidification cracking, etc.). During casting, thermally induced stresses are partially relieved by permanent deformation. When these residual stresses overcome the deformation limit of the alloy, cracks are generated either during solidification (hot tears) or during cooling (cold cracks). The formation of these cracks results in rejection of the cast part. Furthermore, thermally induced stresses can cause downstream processing issues during the sawing stage prior to rolling. For large ingot formats and high strength alloys, sawing becomes a delicate task owing to the risk of saw pinching or crack initiation ahead of the saw. The use of wipers during casting largely reduces the level of as-cast stresses.

The computation of stresses during DC casting of aluminum alloys has been the scope of several studies since the late 90's [210] and is a well established technique nowadays. Many numerical models have allowed researchers to compute the ingot distortions and the associated residual stresses. The validation of these models was often done by comparing the computed and measured ingot distortions, e.g. the butt-curl [8] and the rolling face pull-in for rolling sheet ingots produced by DC [9] or electromagnetic casting [11].
Validation against the computed room-temperature residual stresses is limited simply owing to the difficulty of measuring the internal strains and the high variability in the measurements. While some measurements are available for quenching [12] or welding [13], they remain rare, uncertain and usually are limited to one or two components of the stress tensor, and to the skin of round billets for as-cast materials [14-15]. In contrast to destructive methods for measuring residual stresses (hole-drilling strain gage, cut compliance, layer removal technique), physical methods such as neutron, X-ray or ultra-sound diffraction are very attractive [16] since they can yield all stress components. In addition, the use of physical methods allows for measurements deep within a sample up to the energy limit of the beam. With the development of powerful neutron beams, it is now possible to measure residual strains rather deep in light metal alloys such as aluminum and magnesium since these metals are relatively transparent to neutrons [17-18], as opposed to copper and iron. Such measurements allow for sophisticated model validation. This has been done for AA6063 extrusion billets cast at different speeds and measured at two different diffractometers. Using a FE model to compute the stress build-up during casting [18] together with the thermal and mechanical properties, the sawing itself was modeled by the removal of elements, similarly to the strategy adopted by Drezet et al. [19] to study possible crack initiation and propagation. The authors showed that a minimum billet sectionlength of a least three times the billet radius was required to ensure that the residual stresses at its mid-height are not relaxed during sawing. The validation of the FE casting model against residual stresses in aluminum round billets is fully detailed in [18, 20]. The aim of the present work is to extend this validation to the case of rolling plate ingots and to assess the benefits of using a wiper during casting.

Residual strain measurements have been undertaken on two rectangular AA7050 rolling plate ingots $300 \mathrm{~mm}$ in thickness, 600 $\mathrm{mm}$ in width and $1 \mathrm{~m}$ in length cast at $90 \mathrm{~mm} / \mathrm{min}$. One ingot is cast with the use of a wiper, the second without it. Residual stress measurements have been carried out at the neutron diffractometer SALSA at ILL-Grenoble, France [21]. The goal of the present work is:

- to quantify the level of as-cast residual stresses in the foot of the slab,

- to compare the measured residual stresses with those predicted by the DC casting finite element (FE) model developed by Drezet et al. [1, 2], 
- $\quad$ and to quantify the reduction of internal stresses when using a wiper.

Section II provides a description of the material and the principles of residual stress measurement using neutron diffraction. The finite element (FE) model of the DC casting process is briefly recalled in section III. The measurements are presented in section VI and compared with the values predicted by the three dimensional FE casting model.

\section{M aterial and residual stress measurement techniques}

\section{$\underline{2.1 \text { Material }}$}

The AA7050 alloy is a heat treatable alloy from the 7xxx series alloy containing $\mathrm{Zn}, \mathrm{Mg}, \mathrm{Cu}$ and $\mathrm{Zr}$. Its temperature of end of solidification, rigidity (corresponding to the onset of thermal contraction) and liquidus temperatures were calculated using the software ProPHASE proposed by Sigli et al. [22].

In order to reduce possible cracking during and after casting, high strength aluminum alloys are usually cast with a wiper placed on its surface as schematically shown in fig. 1 . The wiper ejects the running water from the ingot surface and thus reduces the efficiency of cooling. The ingot being hotter, internal stresses are partially relaxed during casting.

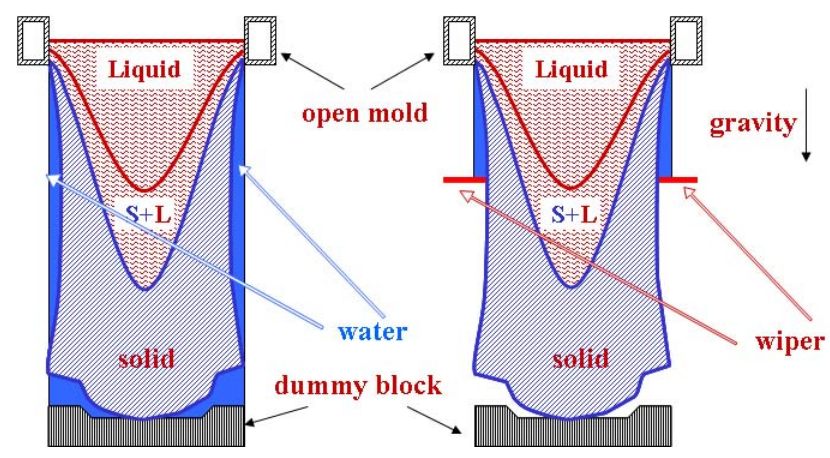

Figure 1: schematics of the use of a wiper for casting high strength aluminum alloys.

Two 1 meter long rolling plate ingots were cast semi-continuously at the experimental cast house at Constellium CRV, Voreppe, France. After the transient start-up phase, the casting speed was set to a steady state speed of $90 \mathrm{~mm} / \mathrm{min}$. The first ingot was cast with a wiper. Keeping all casting parameters constant as much as possible, the casting team managed to cast the second ingot without a wiper. Both ingots were wrapped in security nets in case of erratic explosion and transported to Institut Laue Langevin, Grenoble, for neutron diffraction residual stress measurements. The weight of each sample was slightly lower than $500 \mathrm{~kg}$. Typical grain size in this casting was $100+/-30$ microns with a globular microstructure due to the use of grain refiner.

\subsection{Neutron diffraction measurements}

SALSA [20] is a neutron diffraction instrument designed for strain measurements through the accurate determination of lattice spacing. In a stressed material, the lattice spacing acts as a kind of strain gauge. The elastic strain is given by $\varepsilon=(\mathrm{d}-\mathrm{d} 0) / \mathrm{d} 0$, where $\mathrm{d} 0$ and $\mathrm{d}$ are, respectively, the stress-free and actual lattice spacing for a given crystal plane family. Using Hooke's law, the measured strain can be converted to stress with the appropriate elastic constants. Diffraction can be understood in terms of the Bragg's law $\lambda=2 \mathrm{~d} \sin \theta$ where $\mathrm{d}$ is the lattice spacing, $\lambda$ the wavelength and $2 \theta$ the diffraction angle. Therefore in order to measure the lattice spacing for determining strains and stresses, either the wavelength is fixed and the diffraction angle is measured (monochromatic angular dispersive) or the diffraction angle is fixed and the wavelength determined (polychromatic time-offlight). In the case of monochromatic neutron source where only one diffraction peak is recorded, for fcc metals such as aluminum, the (311) diffracting planes are commonly used to measure the strain since they do not accumulate significant intergranular stresses and hence exhibit similar behavior as that of the bulk. The (311) is also recommended for use in the measurement of residual strains by neutrons in aluminum alloys by the ISO VAMAS standard [23]. A series of stress free reference samples, for measurement of the reference lattice constant $\mathrm{d}_{0}$, were also acquired. These samples were electro-discharge machined along the casting direction at the symmetry plane of the slab every 20 $\mathrm{mm}$ in order to account for any variation in $\mathrm{d}_{0}$ that may be present due to long range chemical inhomogeneities, i.e. macrosegregation. Located at ILL-Grenoble, SALSA uses a large crystal monochromator to select a particular neutron wavelength. The material to be studied is placed in this monochromatic neutron beam, and the scattered neutrons are collected on a large $2 \mathrm{D}$ detector to determine accurately the lattice spacing. The wavelength is constant (1.66 $\AA$ ) and the position of the diffraction peak is recorded on a position sensitive detector. For the measurements at SALSA, $2 \mathrm{~mm}$ radial focusing collimators were used to reduce experimental errors introduced by the optics. The instrumental gauge volume was set to $2 \times 2 \times 4 \mathrm{~mm} 3$ as strains may vary in all directions during the transient start up phase.

\subsection{Residual stress state in as-cast ingots}

In DC cast extrusion billets [20], the elastic stress and strain tensors have only four components due to the axisymmetric billet geometry and casting conditions. For rolling slabs, this is no longer the case and the stress/strain tensor has 6 components. The strain measurements were carried out in the orthogonal $(\mathrm{x}, \mathrm{y}, \mathrm{z})$ reference frame (axis $\mathrm{z}$ is along casting direction and gravity, axis $\mathrm{x}$ is along the width of the ingot and axis $\mathrm{y}$ along its thickness) along four scan lines, OA, DE, DF and BC. The location of these scan lines are depicted in figure 2 where only one quarter of the slab is represented owing to the presence of the tow symmetry planes. Points D and B are located $85 \mathrm{~mm}$ and $250 \mathrm{~mm}$ above point $\mathrm{O}$, respectively.

Applying Hooke's law with a Young's modulus E (71.3 GPa) and a Poisson's ratio $v(0.3)$, the stress components along each axis write:

$$
\begin{aligned}
& \sigma_{x x}=2 \mu \varepsilon_{x x}+\lambda\left(\varepsilon_{x x}+\varepsilon_{y y}+\varepsilon_{z z}\right) \\
& \sigma_{y y}=2 \mu \varepsilon_{y y}+\lambda\left(\varepsilon_{x x}+\varepsilon_{y y}+\varepsilon_{z z}\right) \\
& \sigma_{z z}=2 \mu \varepsilon_{z z}+\lambda\left(\varepsilon_{x x}+\varepsilon_{y y}+\varepsilon_{z z}\right)
\end{aligned}
$$

where $\lambda$ and $\mu$ are the Lamé's coefficients:

$$
\lambda=\frac{v E}{(1+v)(1-2 v)} \quad \text { and } \quad \mu=\frac{E}{2(1+v)}
$$




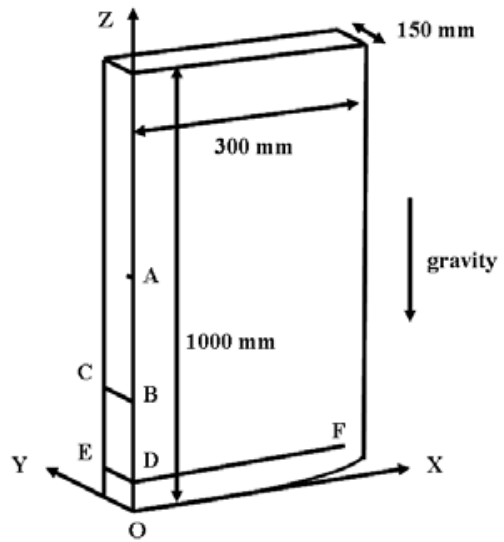

Figure 2: reference frame (xyz) and the 4 scan lines, OA, DE, BC and DF along which $\mathrm{xx}$, yy and zz strain components have been measured. Point $\mathrm{O}$ is the centre lower point of the slab. One quarter of the ingot is represented owing to the two symmetry planes.

For each of the three measured strain components, both the beam orientation and the position of the ingot within the neutron chamber must be varied. The length of the beam path varies from almost zero at the ingot surface to values of the order of the ingot thickness i.e. $300 \mathrm{~mm}$. In that case, time measurements are greatly longer. Residual stresses have also been measured at CRV at the ingot surface at points $0, \mathrm{E}, \mathrm{C}$ and $\mathrm{F}$ using the hole drilling method [16]. Special attention was paid not to initiate a crack, especially in the ingot cast without a wiper. Figure 3 shows a picture of the ingot in place in the neutron chamber (left) and the hole drilling measurement (right).

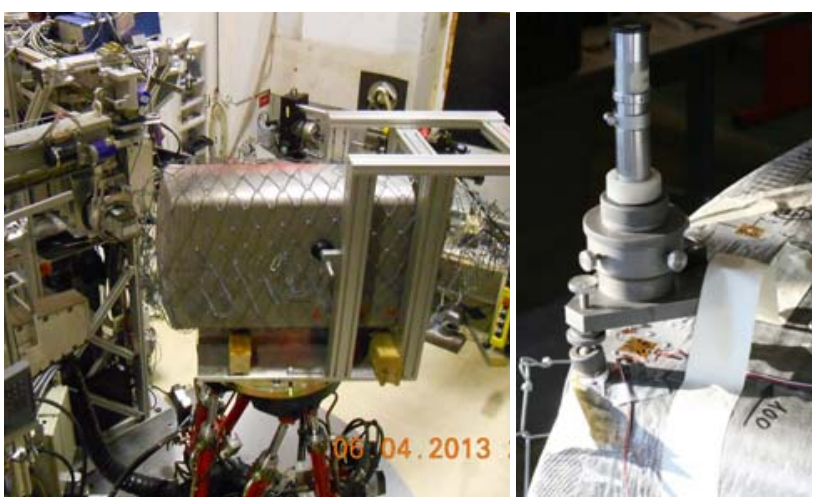

Figure 3: ingot positioning for measuring residual stresses at SALSA (left) and hole drilling measurement at CRV (right).

\section{Thermomechanical model of casting}

The DC casting process of rectangular rolling plate ingot was simulated using a transient three dimensional coupled thermal mechanical model implemented in the commercial finite element code ABAQUS ${ }^{\circledR}$ 6.10. Due to symmetry, the computational domain includes one quarter of the ingot. The mesh consists of 50 layers of elements, with each $20 \mathrm{~mm}$-high layer containing 75 elements, for a total cast length of $1000 \mathrm{~mm}$. The coordinate system (x,y,z in fig. 2) was fixed with respect to the slab and the incoming flow of liquid metal was modeled through the activation of successive layers at a rate that corresponds to the experimental casting speed of $90 \mathrm{~mm} / \mathrm{min}$. The total simulation time was $1500 \mathrm{~s}$ for the casting per se plus a $3600 \mathrm{~s}$ cool-down period. A typical CPU time of 10 hours was required to run each calculation. The initial condition was a pouring temperature of $670^{\circ} \mathrm{C}$. The lateral boundary conditions were moved up along $\mathrm{z}$, i.e. along the casting direction, at a rate of $90 \mathrm{~mm} / \mathrm{min}$. These boundary conditions account for primary cooling through the mould, air gap formation and secondary cooling at the point where the water hits the ingot and flows along its surface [24]. To simulate the presence of a wiper, an adiabatic condition was used below the location of the wiper. The heat transfer to the dummy block was simplified and modeled using a mean heat transfer coefficient of $200 \mathrm{~W} / \mathrm{m}^{2} \mathrm{~K}$.

The mechanical properties of the AA7050 alloy were taken from the work of Lalpoor et al. [25, 26]. Further details on the FE model of casting can be found in [1, 2, 8, 9, 20]. Figure 4 shows the computed temperature distribution and extension of the mushy zone (solid volume fractions between 0.0 and 1.0) in the absence of a wiper (left) and when a wiper is used (right). The solid part of the ingot remains above $200^{\circ} \mathrm{C}$ when a wiper is used and the mushy zone gets slightly deeper.

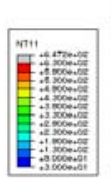

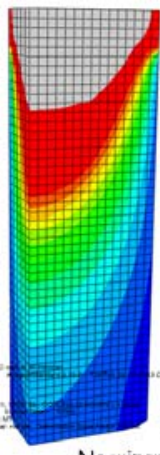

No wiper

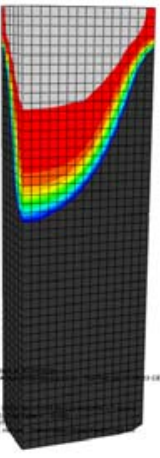

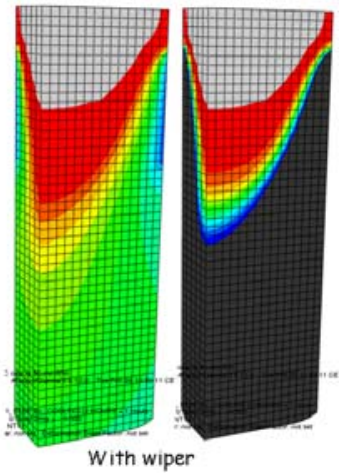

With wiper
Figure 4: influence of a wiper on temperature distribution and mushy zone extension during casting. Grey regions correspond to the liquid phase.

\section{Computed and measured residual stress profiles}

In this section, measured as-cast residual stress profiles are compared with the computed ones along the four scan lines OA, $\mathrm{DE}, \mathrm{DF}$ and BC. Fig. 5 shows the $\mathrm{xx}$, yy and zz stress component distribution along the axis OA, i.e. along the axis of symmetry of the ingot (cf. fig. 2) when casting was performed without a wiper. Fig. 6 shows the same distributions but when using a wiper. A similar scale is used to better see the differences in terms of stress level. Both distributions exhibit the same trends and are rather well reproduced by the FE model: a bi-axial compression stress state at the very bottom of the ingot and a transition to a tri-axial stress state after a cast length of $50 \mathrm{~mm}$. As expected, the stress level is much lower when a wiper is used, roughly $35 \%$ lower. In the absence of a wiper, the xx stress component goes through a maximum at a cast length of $120 \mathrm{~mm}$ before reaching a plateau. This effect is less pronounced with the presence of a wiper. 


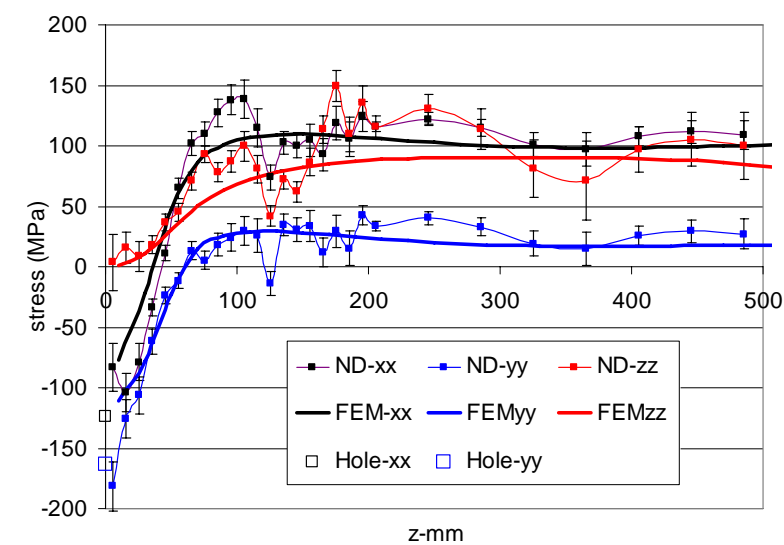

Figure 5: computed and measured stress profiles along OA for the ingot cast without a wiper. ND stands for neutron diffraction and FEM for finite element modeling.

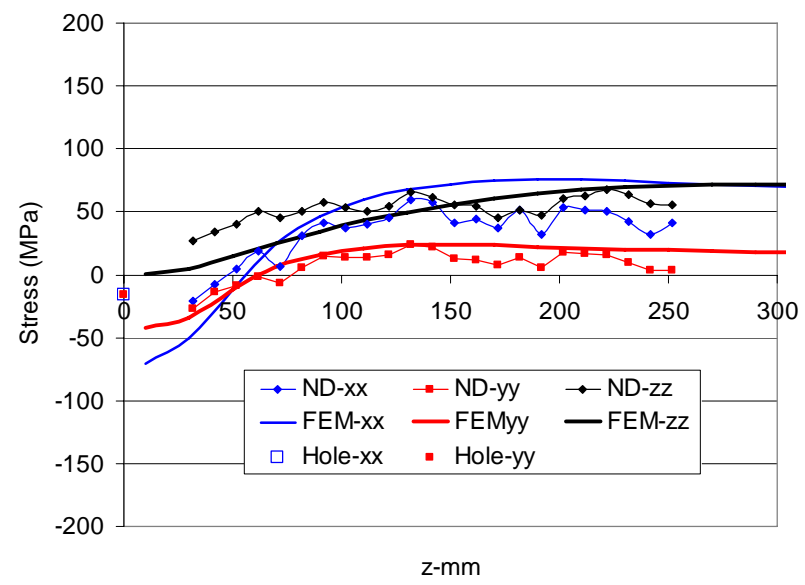

Figure 6: computed and measured stress profiles along OA for the ingot cast with a wiper.

The results using the hole drilling method are also reported at the bottom of the ingot $(x=0)$ and agree well with the overall distributions, especially in the ingot cast without a wiper.

Fig. 7 shows the stress distribution along the scan line DE, i.e. along a short side close to the foot of the ingot (cf. fig. 2) cast without a wiper. Fig. 8 shows the same distributions but when using a wiper. The surface is in bi-axial compression stress state whereas the center is in tri-axial tension. Again, stresses are much lower when a wiper is used during casting. The FE model underestimates the $\mathrm{xx}$ stress component at the surface whereas both hole drilling and neutron diffraction techniques give comparable results.

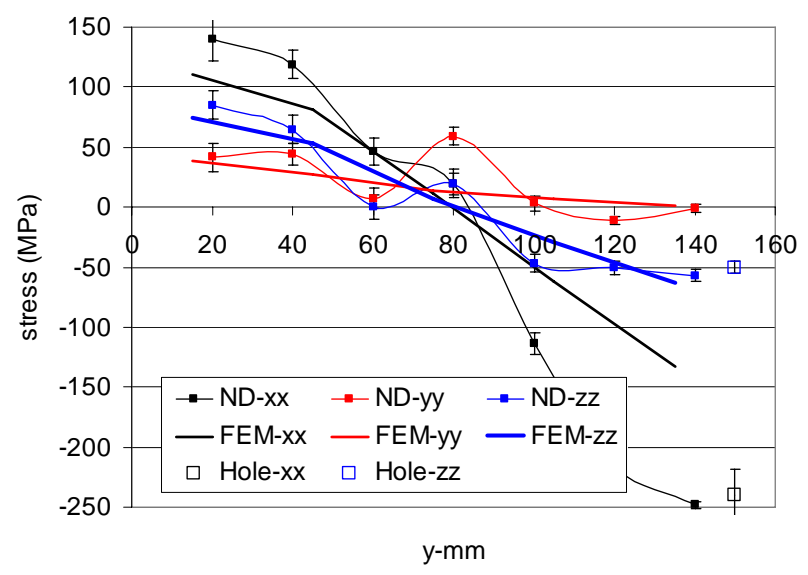

Figure 7: computed and measured stress profiles along DE f or the ingot cast without a wiper.

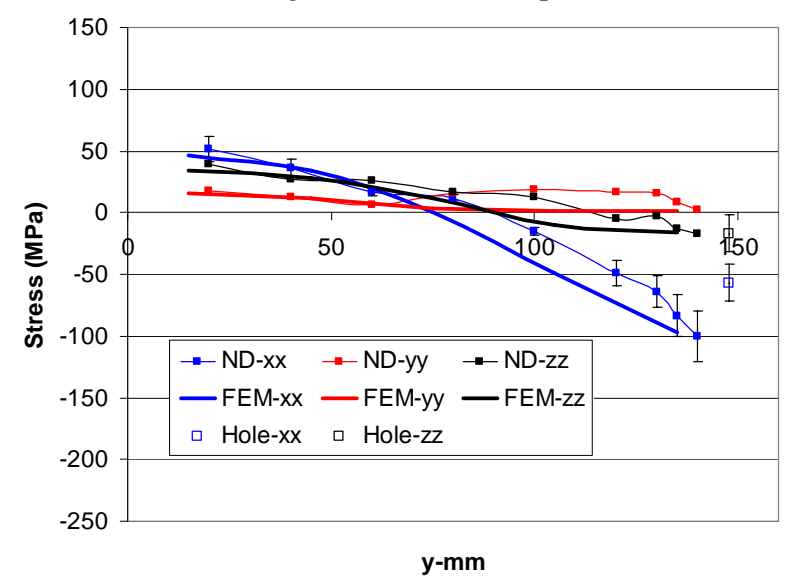

Figure 8: computed and measured stress profiles along DE for the ingot cast with a wiper.

Fig. 9 and 10 present the stress distribution along the axis DF, i.e. along a long side close to the foot of the ingot (cf. fig. 2) when casting was performed without a wiper and with a wiper, respectively. It is interesting to notice that the yy and $\mathrm{zz}$ stress components both exhibit a maximum when going from tension close to the symmetry axis $(\mathrm{x}=0)$ to compression at the surface. This result gives valuable information to study sub-surface crack initiation and propagation. It is in agreement with the work of Boender et al. [6] who analyzed J cracks that initiate at the ingot surface in the mold and then propagate in zones of high tensile stresses. 


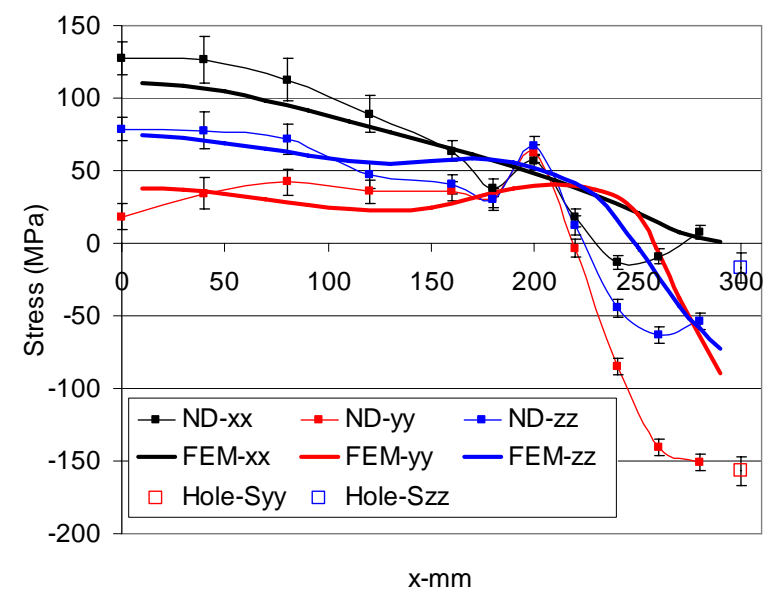

Figure 9: computed and measured stress profiles along DF for the ingot cast without a wiper.

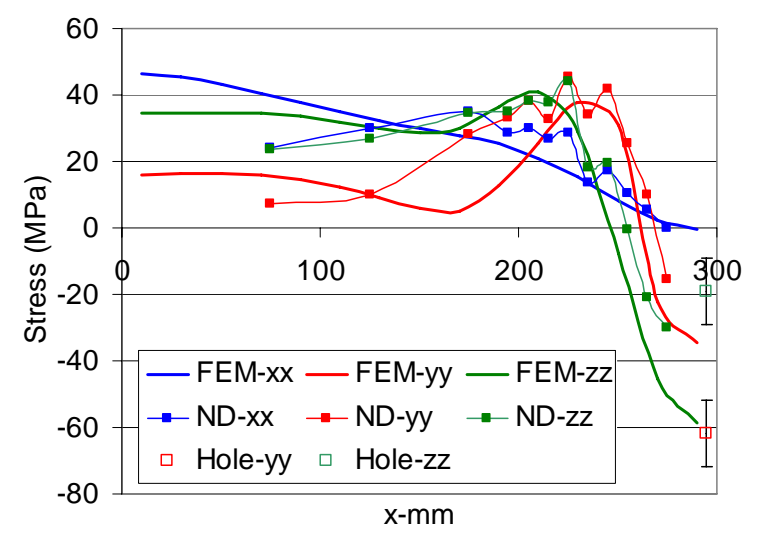

Figure 10: computed and measured stress profiles along DF for the ingot cast with a wiper.

Fig. 11 shows the stress distribution along the scan line BC located $165 \mathrm{~mm}$ above segment DF (cf. fig. 2) when casting was performed without a wiper. The same distribution is presented in fig. 12 but with comparison only with results at the surface using the hole drilling method.

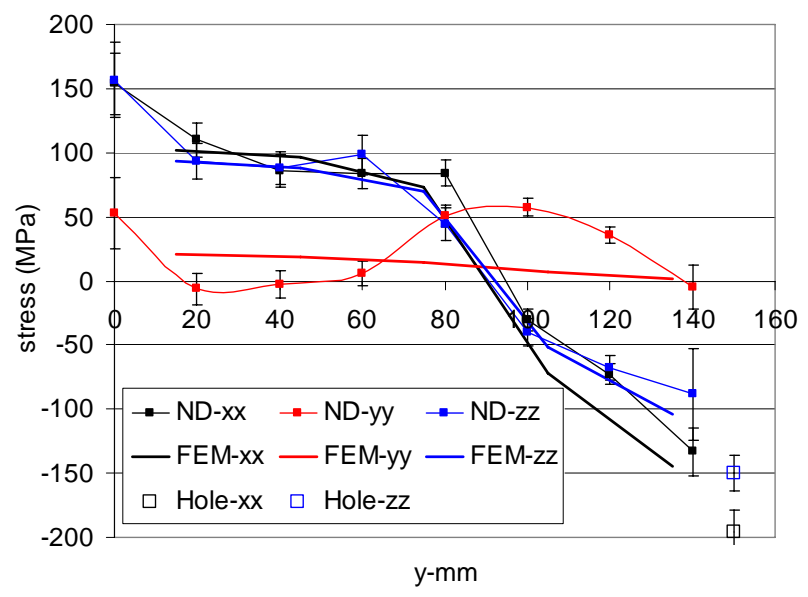

Figure 11: computed and measured stress profiles along BC for the ingot cast without a wiper.
Both distributions are similar to these found for the scan line DE except a lower compression level at the ingot surface is found.

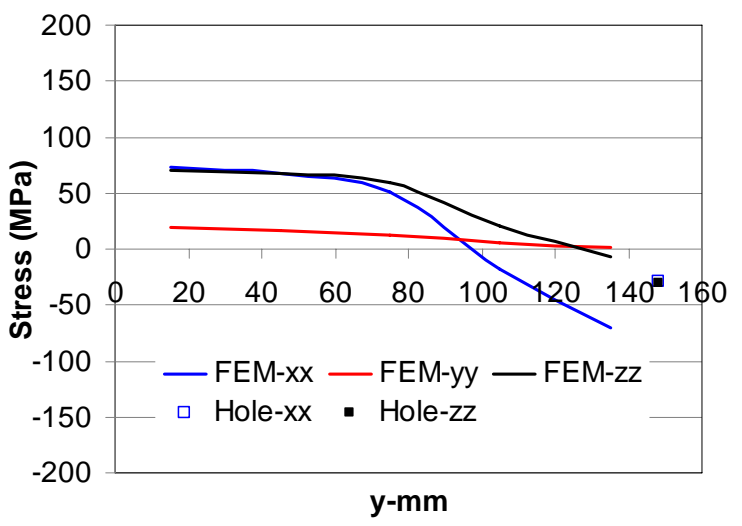

Figure 12: computed stress profiles along BC for the ingot cast with a wiper.

The overall agreement between FE results and measured values induces confidence in the casting numerical model. This allows us to be more quantitative in the stress reduction owing to the use of a wiper during casting. Fig. 13 shows the computed distribution of the Von Mises equivalent stress along the symmetry axis (cf. fig. 2). High values are found at the very bottom of the ingot owing to the high cooling through the dummy block. Then values exhibit a minimum before reaching a plateau in the steady state regime of casting, i.e. when heat transfer operates through the lateral surfaces of the slab. The mean reduction of $33 \%$ in the stress level is explained by the fact that the ingot remains hot during casting with a wiper, typically above $200^{\circ} \mathrm{C}$ (cf. fig.4). At these temperatures, the strain rate sensitivity of the AA7050 alloy is not nil [25] and stresses are relaxed by visco-plastic deformation.

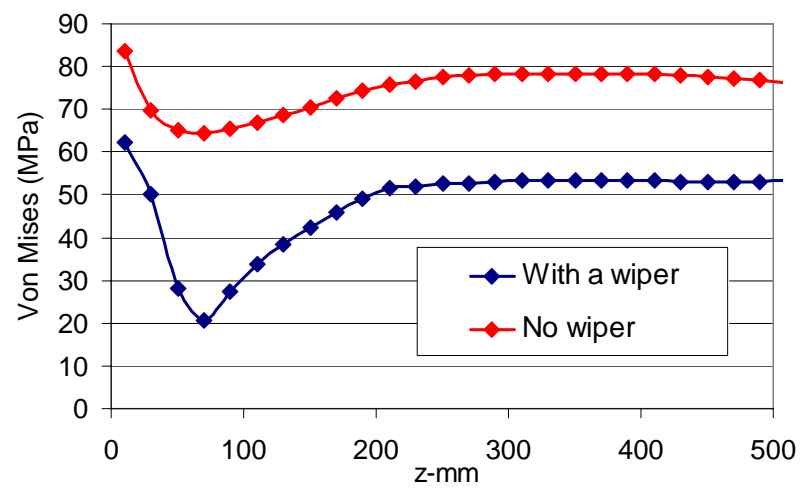

Figure 13: influence of using a wiper on the Von Mises equivalent stress along the symmetry axis.

\section{Conclusion}

As-cast residual stresses have been measured on two AA7050 rolling plate ingots cast with and without a wiper. Neutron diffraction measurements have been carried out at SALSA, ILLGrenoble, and hole drilling measurements at CRV, Voreppe. All measured results were compared with the values given by a thermomechanical FE model of DC casting. Considering the numerous input parameters entering into the model (alloy 
properties, cooling conditions, as-cast rheology, etc.), the casting model is able to reproduce the measured stresses and yields a $33 \%$ reduction in the internal stress level when a wiper is used during casting. Similarly to the situation reported for round billets, ascast rolling plate ingots exhibit tri-axial tension at their interior and bi-axial compression at their surfaces. Directions of improvement of the present FE model of casting reside in a better description of:

- the heat transfer to the dummy block taking into account the formation of an air-gap (butt-curl)

- $\quad$ and the as-cast rheology of the alloy with special attention to its mechanical coherency temperature (onset of thermal contraction).

For the last point, it is envisaged to use neutron diffraction in a time resolved manner to detect the very moment a solidifying alloy can transmit tensile strains and stresses.

\section{Acknowledgements}

The authors express their acknowledgements to Constellium CRV, Voreppe, for casting and providing the two rolling ingots for neutron diffraction measurements and to the international Neutron Source at ILL for the provision of beam time.

\section{R eferences}

1. J.-M. Drezet "Direct Chill and Electromagnetic Casting of Aluminium Alloys: Thermomechanical Effects and Solidification Aspects", PhD work no. 1509, EPF-Lausanne, July 1996. http://library.epfl.ch/en/theses/

2. J.-M. Drezet, M. Rappaz, Modelling of Ingot Distortions during Direct Chill Casting of Aluminium Alloys , Met. Mat. Trans. A, 27A, 1996, pp. 3214-3225.

3. B. Hannart, F. Cialti, R. V. Schalkwijk, Thermal Stresses in DC Casting of Aluminum Slabs: Application of a Finite Element Model, Light Metals 1994, A. T. Tabereaux Ed., TMS, 1994, pp. 879-887.

4. H. Fjaer and A. Mo: Alspen: a mathematical model for thermal stresses in direct chill casting of aluminium billets, Met. Mat. Trans. A, 21B, 1990, pp. 1049-1061.

5. J. Sengupta, S.L. Cockcroft, D.M. Maijer, A. Larouche, Quantification of temperature, stress, and strain fields during the start up phase of DC casting process by using a $3 D$ fully coupled thermal and stress model for AA5182 ingots, Mat. Sc. Eng A, 397, 2005, pp. 157-177.

6. W. Boender, A. Burghardht, E. P. van Klaveren, J, Rabenberg, Numerical Simulation of DC casting, Interpreting the results of a Thermo-Mechanical Model, Light Metals 2004, A. T. Tabereaux Ed., TMS, 2004, pp. 679-684.

7. O. Ludwig, J.-M. Drezet, B. Commet, B. Heinrich, Modelling of Internal Stresses in DC casting and Sawing of High Strength Aluminum Alloys slabs, in Modeling of Casting Welding and Advanced Solidification Processes, Eds. C.-A. Gandin and M. Bellet, pp. 185-192, Nice, 2006.

8. W. Droste, J.-M Drezet, G.-U Gruen and W. Schneider: 3D Modeling of Ingot Geometry Development of DC-cast Aluminium Ingots during the Start-up Phase, in Continuous Casting, Eds: K. Ehrke and W. Schneider, DGM, WileyVCH, Frankfurt 2000, pp. 175-183.
9. W. Droste, G.-U Grün, W. Schneider and J.-M. Drezet : Thermo-Mechanical Modeling to Predict Shrinkage, Shape and Mold Openings for DC-Cast Rolling Ingots, in Light Metals, Eds. Wolfgang Schneider, TMS 2002, Seattle, pp. 703-708.

10. A.B. Phillion, D. Maijer and S.L. Cockcroft: Coupled Thermal-Stress Model of the Start-up Phase of the Aluminum Direct Chill Casting Process: Predictions Relating to Hot Tearing in Model Casting, Welding \& Adv Solidif Proces XI, TMS, (2006), 807-814.

11. J. W. Evans: The use of electromagnetic casting for Al. alloys and other metals, Journal of metals, TMS, May 1995, pp. 38-41.

12. K. Escobar et al.: On the residual stress control in aluminium alloys 7050, Materials Science Forum vols. 396-402 (2002), p. $1235-1240$.

13. S. Ganguly, M. E. Fitzpatrick and L. Edwards: Comparative neutron and synchrotron $X$-rax diffraction studies to determine residuals stress on an as-welded AA2024 plate, Materials Science Forum vols. 790-491 (2005), pp. 223-228.

14. J. Moriceau: Thermal stresses in continuous DC casting of Al alloys, discussion of hot tearing mechanisms, Light Metals (TMS), 1975, p. 119-133

15. S. A. Levy et al.: Residual stress measurements for studying ingot cracking, Light Metals (TMS), 1974, p. 571-585.

16. J. Lu, Handbook of Measurement of residual stresses, Society for Experimental Mechanics, Inc. The Fairmont Press, Ed. J. Lu, 1996.

17. H. Hao, D.M. Maijer, M.A. Wells, S.L. Cockcroft and R.B. Rogge, Prediction and measurement of residual stresses/strains in a direct chill casting magnesium alloy billet in Magnesium Technology, (2005), 223-228.

18. J.-M. Drezet and A. Phillion: As-cast residual stresses in an aluminum alloy AA6063 billet: neutron diffraction measurements and finite element modeling, in Met. and Mat. Trans. Vol. 41 A, pp. 3396-3404, December 2010.

19. J.-M. Drezet, O. Ludwig, C. Jaquerod and E. Waz: Fracture prediction during sawing of DC cast high strength aluminium alloy rolling slabs in Inter. Journal of Cast Metals, 2007, vol. 20, no. 3, p. 163-170.

20. J.-M. Drezet, Th. Pirling and C. Jacquerod: Residual stresses in as-cast billets: neutron diffraction measurement and thermomechanical modeling, in Light Metals 2012, Ed. Carlos E. Suarez, TMS, pp. 1117-1122.

21. Strain imager for engineering applications SALSA, Institut Laue Langevin, Grenoble, France http://www.ill.eu/instruments-support/instrumentsgroups/instruments/salsa/

22. C. Sigli, L. Maenner, C. Sztur and R. Shahani, Phase diagram, solidification and heat treatment of aluminium alloys, Proc. International Conference on Aluminum Alloys, T. Sato, S. Kumai, T. Kobayashi and Y. Murakami Eds, JILM, 1998, pp.87-98.

23. G.A. Webster: VAMAS TWA 20 standard, ISO Technical report, 2001

24. J.M. Drezet, M. Rappaz, G.U. Grun and M. Gremaud: Met. Trans. A, 2000, vol. 31, pp. 1627-34.

25. M. Lalpoor et al., Met. Trans. A, vol. 40, pp. 3304-3313.

26. M. Lalpoor et al., Met. Trans. A, vol. 41, pp. 2425-2434

27. J.-M. Drezet, A. Evans, C. Jaquerod and A. Phillion in Jim Evans Honorary Symposium, Eds. B. Li, B. Thomas, L. Zhang, F.-M. Doyle and A. Campbell, TMS, 2010, pp. 4352. 